\title{
Operationalization of Insecticide Resistance Monitoring Amongst Malaria Vectors in the Philippines
}

Salazar FV' ${ }^{1 *}$, Malijan RPB ${ }^{1}$, Braganza JB ${ }^{1}$, Angeles JR ${ }^{1}$, Ammugauan MAT ${ }^{1}$, Aguila AMA ${ }^{1}$, Macam $\mathrm{OL}^{2}$, Segundo $\mathrm{UP}^{3}$, Ebol AP ${ }^{4}$, Hugo $\mathrm{CT}^{5}$, Torno MM${ }^{1,6}$, Aure $\mathrm{WE}^{1}$, Velayudhan $\mathrm{R}^{7}$ and Espino $\mathrm{FECJ}^{8}$

${ }^{1}$ Department of Medical Entomology, Research Institute for Tropical Medicine, Philippines

${ }^{2}$ Mimaropa Center for Health Development, Quezon City, Philippines

${ }^{3}$ Cordillera Center for Health Development, Baguio City, Philippines

${ }^{4}$ Davao Center for Health Development, Davao City, Philippines

${ }^{5}$ Asian Collaborative Training Network for Malaria, Manila, Philippines

${ }^{6}$ Environment Health Institute, Ministry of Sustainability and the Environment, Singapore

${ }^{7}$ Department of Control of Neglected Tropical Diseases (HTM/NTD), World Health Organization, Switzerland

${ }^{8}$ Department of Parasitology, Research Institute for Tropical Medicine, Philippines

*Corresponding author: Ferdinand V Salazar, Department of Medical Entomology, Research Institute for Tropical Medicine, Alabang, Muntinlupa City, Metro Manila 1781, Philippines, Email: fervillzar@yahoo.com

\section{Abstract}

Background: Insecticide-based vector control interventions, insecticide-treated nets and indoor residual spraying have been documented to reduce malaria incidence propelling the Philippines towards malaria elimination. These gains should however be sustained by the prevention, retardation and management of insecticide resistance that may cause revulsion in disease and mortality. It is therefore imperative to track development of resistance and monitor their frequencies and distribution.

Methods: Three methods were explored to monitor resistance in malaria vectors: dose response assays, use of knockdown time and the WHO standard bioassay method using diagnostic concentrations.

Results: Local discriminating dose of $0.01 \%$ was established on Anopheles flavirostris for both alphacypermethrin and deltamethrin. Use of knockdown time showed differences in susceptibilities across strains. Results from WHO standard bioassay method across different provincial sites generally showed susceptibility of An. flavirostris strains to pyrethroids (permethrin, deltamethrin, cyfluthrin, lambdacyhalothrin and etofenprox), organophosphates (malathion and fenitrothion), carbamates (propoxur and bendiocarb) and the organochlorine compound (DDT). However, resistance was detected in several strains of An. flavirostris and An. maculatus s.l. to some of the pyrethroids tested.

Conclusion: Continuous monitoring of insecticide resistance captures trends that signals for change in vector control options. It is highly recommended that behavioral changes of target vectors be also observed to decipher if the real cause of resistance is physiological rather than avoidance.

Keywords: Insecticide Resistance; Philippines; Malaria; Vectors 


\section{Introduction}

The Philippines is traversing the path towards malaria elimination; showing significant reduction in the number of malaria cases (by $87 \%$ from 48,569 in 2003 to 6,120 cases in 2020) and in mortality (by 98\% reduction from 162 deaths in 2003 to 3 deaths in 2020) [1]. A total of 60 of the 81 provinces were pronounced malaria-free. Malaria transmission remains in the two remaining provinces of Palawan and Sultan Kudarat while the remaining 19 provinces currently have no local transmission and pending assessment for subnational malaria-free declaration [2]. Malaria transmission occurs typically in forested to forest edges in hilly to mountainous areas where freshwater is generally available for larval breeding [3-5]. Plasmodium falciparum dominates with $88.29 \%$ of the cases, $P$. vivax comprises $9.42 \%$ of cases while the remaining $1.41 \%$ are mixed species and $0.88 \%$ reflects other species [1]. Standard localized intervention measures include early case detection and treatment, use of primaquine to cut transmission, use of rapid diagnostic tests and microscopy to record and report cases. The scaled-up operations on the use of long-lasting insecticidal nets (LLIN) and indoor residual sprays (IRS) significantly contributed to the reduction of cases leading to elimination [6]. The Department of Health-National Malaria Control and Elimination Program (DOH-NMCEP) continues to envision and work toward a malaria-free country by 2030 even with the COVID-19 pandemic impacting the delivery of services and vector control activities. Despite the malariafree status, most of the provinces remain receptive and/ or vulnerable to malaria transmission due to the presence of vectors. Several provinces continue to report imported cases from Africa and other nearby countries in Asia [7]. This current scenario demands continuous surveillance and establishment of elimination hubs that provide resources to immediately initiate control interventions in cases of reemergence or reintroduction [7]. There are five putative vectors of malaria in the country [8]; with the freshwater breeder, Anopheles flavirostris, considered the primary vector. The secondary vectors An. maculatus, An. mangyanus and An. balabacensis are also freshwater breeders while $A n$. litoralis is a brackish water breeding species.

Early studies reported that the local primary vector An. flavirostris from the municipalities of Malasila and Kidapawan, Cotabato in Mindanao exhibited resistance to dieldrin, cross-resistance to benzene hexachloride and tolerance to DDT [9]. From 1992 to 1996, a series of susceptibility tests were conducted by the Malaria Control Service (MCS), an agency under the Ministry of Health responsible for the control of malaria in the country. Anopheles flavirostris collected from Bulacan province in 1992 showed complete susceptibility (100\% mortality) to DDT $(4.0 \%)$ while those collected from Aurora province showed complete susceptibility to bendiocarb $(0.1 \%)$ [10]. In 1993, complete susceptibility of An. flavirostris from Palawan was reported against deltamethrin (0.0125\%) as well as $A n$. flavirostris samples from Agusan del Sur showing complete susceptibility to deltamethrin $(0.0125 \%)$ and fenitrothion $(0.1 \%)$. Further in 1993, susceptibility tests revealed An. litoralis from Tawi-tawi was completely susceptible to deltamethrin $(0.0125 \%)$ and bendiocarb $(0.1 \%)$. The succeeding MCS report in 1996 showed that An. flavirostris from Palawan was also documented completely susceptible to etofenprox $(0.25 \%)$, lambdacyhalothrin $(0.1 \%)$, cyfluthrin $(0.15 \%)$, and deltamethrin $(0.0125 \%)$. In the same year, An. flavirostris samples from Davao del Norte also showed complete susceptibility to etofenprox $(0.25 \%)$.

In 1991, the national government of the Philippines transferred the central responsibilities, functions, revenues and mobilization efforts to the local (provinces and municipalities) level governance. After this act of decentralization, there was no agency to take on the responsibility for the monitoring of insecticide resistance. In 2001, through a grant from World Health Organization - Western Pacific Region Office (WHO - WPRO) Roll Back Malaria (RBM) program (PHL/MAL/1.2/00101.07.01AW.02), the Medical Entomology Department of the Research Institute for Tropical Medicine (RITM) started a project with the primary aim of establishing a nationwide network to monitor periodically possible changes in insecticide susceptibility, resistance frequency and distribution status among malaria vectors in the endemic regions of the Philippines. The project formed the core network for monitoring insecticide resistance in the three major zones covering malarious areas including Mimaropa (name derived from the acronym of the island group of provinces: Mindoro, Marinduque, Romblon and Palawan), Cordillera and Davao regions. Through this grant, the use of dose response assays was explored as an insecticide resistance monitoring tool. Dose response assays through probit analysis showed range of concentrations that would result to $50 \%$ or $100 \%$ mortality, showing concrete values of compound toxicity to the vector. This method however demanded higher cost to order the impregnated papers from WHO and took time to arrive because the amounts requested do not belong to the $\mathrm{WHO}$ recommended list of insecticide for resistance monitoring. To at least record the trends in relative toxicity between sites, the option to record knockdown times was also explored. From the combination of diagnostic concentrations obtained from dose response assays and the standard concentrations recommended by WHO, knockdown times were recorded. This knockdown recording approach showed trends in relative insecticide toxicity for each site. However, several limitations were also encountered that included the use of large numbers of malaria vectors, which also meant more time needed to 
collect vectors from sentinel sites and more staff to observe knockdown at specified intervals. Both dose response and knockdown approaches had been labor-intensive and more costly. It was decided that the monitoring of insecticide resistance be done using the discriminating (diagnostic) dose provided by WHO for Anopheles vectors to hasten the process, to cover more areas, to tests more insecticides and to become up-to-date useful for disease control programs' consumption. Through the years that the malaria control program relied on insecticide-based vector control interventions (insecticide-treated nets and indoor residual spraying), there has been accompanying challenges for the operationalization of insecticide resistance monitoring in the country. This paper presents insecticide resistance status of malaria vectors in the Philippines albeit the issues and logistical challenges encountered to continuously generate data on resistance from 2001 to present.

\section{Materials and Methods}

\section{Sentinel Sites}

At the start of the RBM project, eight sentinel sites were initially chosen based on malaria endemicity and vector control interventions being implemented: Isabela, Mountain Province and Apayao provinces in northern Luzon; Palawan, Oriental Mindoro and Occidental Mindoro provinces in Mimaropa region; and Davao del Norte and Agusan del Sur provinces in Mindanao. Susceptibility tests were conducted in collaboration with the three core partners; Mimaropa, Cordillera and Davao Centers for Health Development. Apayao province was under a mosquito net treatment project back in 1995 and remained a priority area for development under the government's social reform agenda [11]. Palawan being the largest island in Mimaropa is still the leading province in the region and the whole country in terms of malaria morbidity and mortality [2]. Back in 1999, malaria continued to rank high and remained as one of the 10 leading cause of mortality in the Palawan province with an annual parasite index (API) of $1,269 / 100,000$ population [12]. In the same decade, the Mindoro provinces (Occidental and Oriental) showed high malaria endemicity with Occidental Mindoro; second to Palawan in terms of malaria mortality and morbidity. Davao del Norte was specifically chosen in line with the RBM initiative supported by WHO. Malaria at Davao del Norte ranked sixth among the leading causes of morbidity in Davao region with an average of 30,294 cases per year from 1992-1996 (API=630/100, 0000 pop.) [13]. On the other hand, Agusan del Sur ranked as the third leading province in terms of malaria morbidity and was also a recipient of AusAid grant for the control of malaria through a project implemented by the RITM [14]. After the establishment of the eight sentinel sites, efforts were made to reach other malarious areas to have wider coverage in the monitoring of insecticide resistance. From the initially established sentinel sites in 2001, monitoring covered a total of 20 provinces nationwide (Figure 1 ).

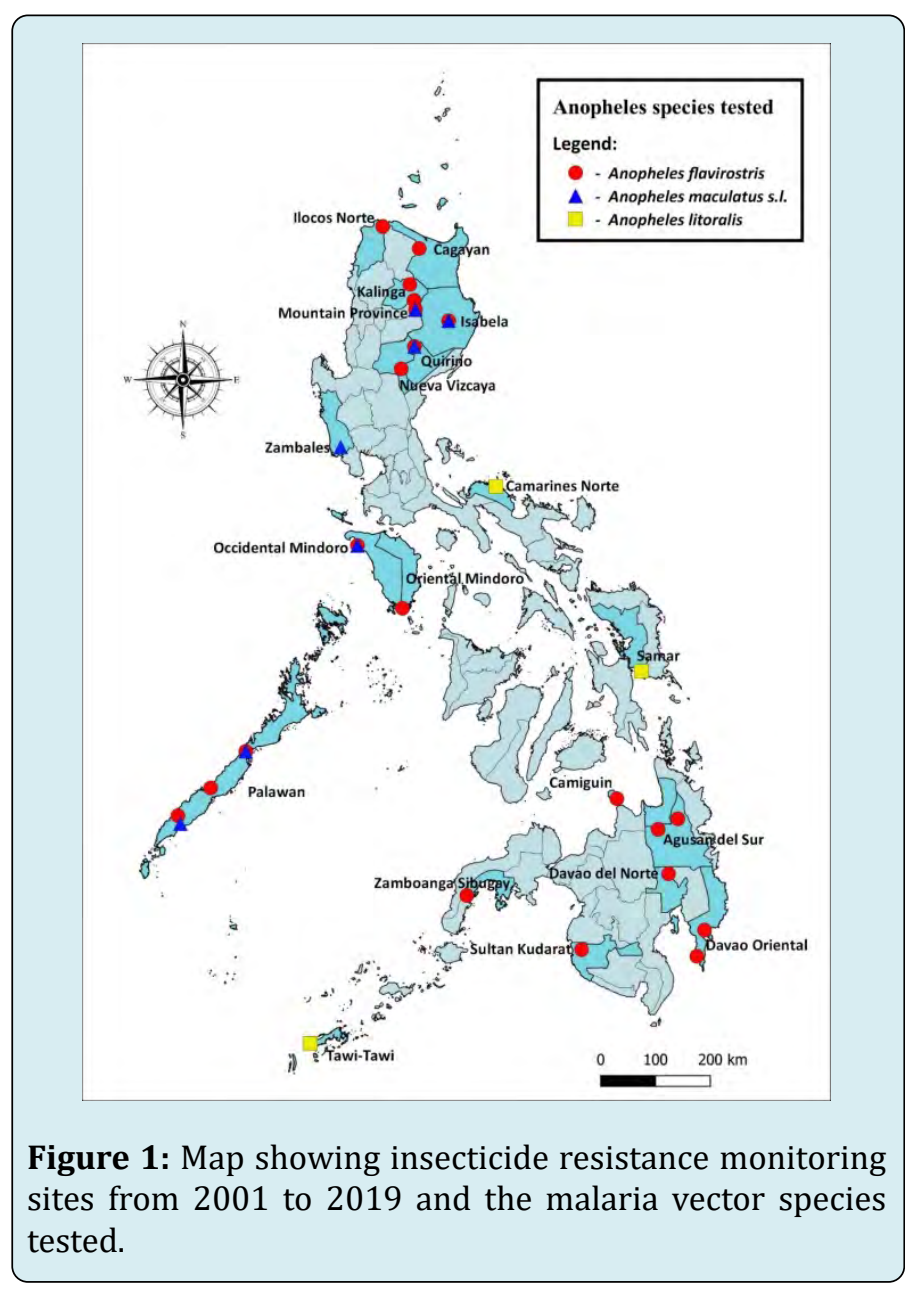

\section{Adult mosquito collections}

Anopheles mosquitoes were collected using carabao (water buffalo) baited traps (CBT) following the procedure described by Salazar et al. [15]. The CBT locations were chosen based on their relative proximity to potential vector larval habitats and approximately 500-meter distance, based on mosquito vector's flight range [8] from the nearest house of a former positive malaria cases. An adult water buffalo (Bubalus bubalis carabanesis) was kept tethered overnight inside the mosquito net with one section of the net remaining open to let mosquitoes freely enter (Figure 2). The net was closed just before the scheduled collections at dawn the following day. All mosquitoes were collected manually from the inside surface of the net using a manual aspirator. Collected mosquitoes were placed in Styrofoam ${ }^{\circledR}$ cups fitted with cloth netting over the open end and were taken to a field-based laboratory for morphological species identification using taxonomic keys [16]. 


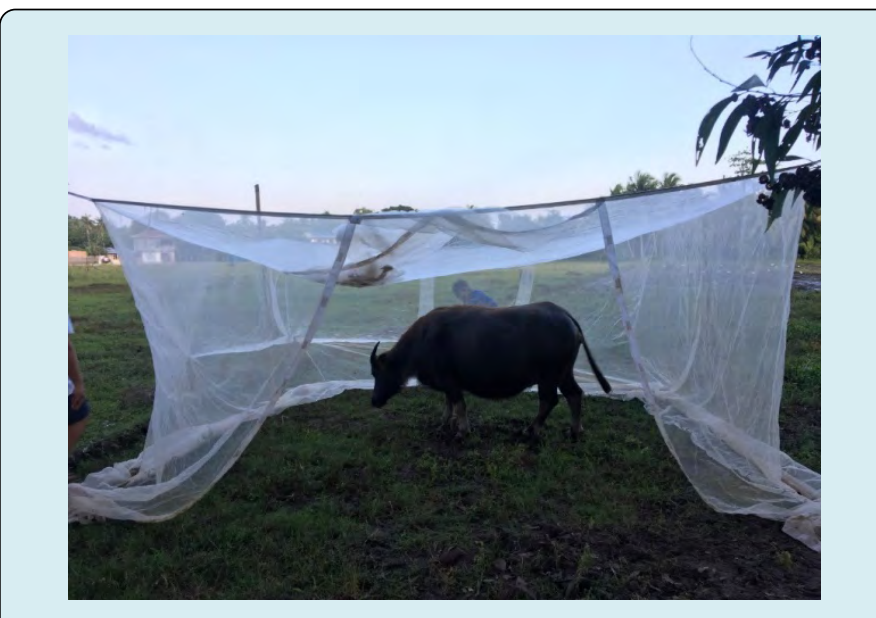

Figure 2: Carabao-baited trap used to collect adult Anopheles mosquitoes for susceptibility testing.

\section{Dose Response Assay and Assessment of Knockdown}

Dose response assay was conducted using WHO standard bioassay procedure for the determination of insecticide susceptibility $[17,18]$. Initial concentrations of deltamethrin and alphacypermethrin-impregnated papers were ordered from Vector Control Research Unit, School of Biological Sciences, Universiti Sains Malaysia (USM), Penang, Malaysia. After the bracketing phase was done, six concentrations $(0.05,0.1,0.2,0.4,1.6$ and $3.2 \mathrm{mg}$ ai/ $\mathrm{m} 2$ ) that resulted in a $5 \%$ to $100 \%$ mortality were sourced from USM for the dose response assays. Typically, 4-5 concentrations were used to better approximate mortality to produce more reliable regression results. Bioassays were conducted in a clean (housing) structure free of insecticide contamination. Insecticide-impregnated papers and controls were lined inside labeled WHO bioassay tubes. Mosquitoes were placed in individual holding tubes and held for 1 hour for acclimatization and to detect any damaged and/or weak mosquitoes due to handling. Mosquitoes found moribund or ailing were replaced before exposure to insecticides. Four to five replicates of 10-15 acclimatized bloodfed female An. flavirostris (or identified and segregated malaria vector species) were then exposed to the impregnated papers for 1 hour. After exposure, mosquitoes were transferred back to clean holding tubes. Test mosquitoes were then provided with 10\% sugar solution. Mortalities from each concentration were recorded after 24 hours. Relative humidity and temperature were noted within the duration of the tests in each sentinel site. No tests were conducted with temperature higher than the $30^{\circ} \mathrm{C}$ to limit the possible effect of high temperatures on the resistance or susceptibility of the test species [19]. The diagnostic concentrations for An. flavirostris from the two insecticides; alphacypermethrin and deltamethrin was computed by doubling $\mathrm{LC}_{99}$. The use of these local discriminating concentrations was evaluated in the following sentinel sites: San Mariano, Isabela; Paluan, Occidental Mindoro; Quezon, Palawan; Tungawan, Zamboanga Sibugay; Kapalong, Davao del Norte; and Bayugan, Agusan del Sur. Due to logistical problems encountered in the use of dose response assays, an alternative option was resorted to come up with indicators and differentiate susceptibility or resistance levels in different monitoring sites. Using the standard WHO diagnostic concentrations and computed local discriminating doses of alphacypermethrin and deltamethrin, knockdown of An. flavirostris was noted at every five minutes interval within one hour of exposure stipulated originally in the earlier (WHO) described procedure. This method provided basis for discriminating resistance from susceptible insects [20]. The time needed (KT or knockdown time on X-axis) to result to 0.1 to $99.9 \%$ Knockdown (Y-axis) of the test population were extrapolated based on knockdown data using probit analysis [21].

\section{Resistance Monitoring using Diagnostic Concentrations}

The use of the WHO diagnostic concentrations started from 2006 to 2019 and remains the preferred method for insecticide resistance monitoring. Susceptibility assays were conducted using diagnostic operational concentrations of insecticide-impregnated papers ordered from USM. From 2006 to 2013, a total of 75 mosquitoes were examined for each insecticide diagnostic concentration with matching noninsecticide controls $[17,18]$. Succeeding procedures used a minimum number of 100 mosquitoes per test insecticide to consider a test valid [22]. Modification of the WHO procedure (i.e. recording of knock down every 5 minutes interval) was made to develop a sensitive detection method and to better see trends of resistance [15]. Mosquito mortalities were recorded after a 24-hour holding period.

\section{Data Analysis}

Analysis of insecticide susceptibility in the dose response assays was done through probit analysis [23] with the aid of a computer program Priprobit ver1.63 [21]. This program provides lethal dosages (or concentrations) based on the slope of each mortality line. Lethal concentration $\left(\mathrm{LC}_{99}\right)$ computed from the susceptibility tests served as reference to compute for the discriminating dosages of the two test insecticides, deltamethrin and alphacypermethrin. The same program provides graphic details of which probit (regression) lines were drawn for comparison. The susceptibility status of mosquitoes to each diagnostic dose of insecticide was evaluated based on World Health Organization criteria $[17,22]$. If necessary, final test mortality 
was adjusted against matched control mortality using Abbott's formula. Mosquitoes were considered susceptible if the percentage mortality was 98 to 100 percent, resistant if mortality was less than $90 \%$ and possibility of incipient resistance if mortality is between $90 \%$ and $<98 \%$ and needs reconfirmation of the resistance [19].

\section{Results}

\section{Dose Response assays}

Baseline alphacypermethrin monitoring revealed a decreasing order of toxicity of the compound to An. flavirostris from the computed $\mathrm{LC}_{50}$ values: Agusan del Sur $<$ Davao del Norte < Kalinga < Palawan < Isabela strains (Table 1). The decreasing order based on $\mathrm{LC}_{99}$ was: Agusan del Sur < Palawan < Davao del Norte < Kalinga < Isabela. Alphacypermethrin's innate toxicity was indicated by the steep slopes showing high mortality response per unit change in insecticide concentration (Figure 3). Highest innate toxicity was observed from Agusan del Sur and Palawan strains while flattest slope was observed from Isabela strain indicative of the least comparative toxicity of alphacypermethrin (Figure 3). Tests conducted on deltamethrin against different strains of An. flavirostris revealed the following decreasing toxicity trend based on the $\mathrm{LC}_{50}$ : Agusan del Sur $<$ Palawan $<$ Davao del Norte < Kalinga < Isabela (Table 2). The following order was recorded based on $\mathrm{LC}_{99}$ : Agusan del Sur $<$ Palawan < Kalinga < Davao del Norte < Isabela. Regression lines show varied responses of each of the strain (Figure 4). The local discriminating dose was computed from the data generated from An. flavirostris Agusan del Sur strain which was the most susceptible amongst all strains from the sentinel sites in the country in 2001 to 2002 baseline monitoring. The computed discriminating dose (twice $\mathrm{LC}_{99}$ ) for alphacypermethrin was $3.06 \mathrm{mg}$ ai $/ \mathrm{m}^{2}(=0.0084 \sim 0.01 \%)$ and for deltamethrin was $3.44 \mathrm{mg}$ ai $/ \mathrm{m}^{2}(=0.0094 \sim 0.01 \%)$.

\begin{tabular}{|c|c|c|c|c|}
\hline Strains & $\mathrm{LC}_{50}\left(\mathrm{mg}-\mathrm{ai} / \mathrm{m}^{2}\right)$ & $\mathrm{LC}_{99}\left(\mathrm{mg}-\mathrm{ai} / \mathrm{m}^{2}\right)$ & Linear Equation/Slope & $\mathrm{X}^{2}$ \\
\hline Agusan del Sur & 0.16 & 1.53 & $Y=1.89+2.34 X$ & 0.40 \\
\hline Kalinga & 0.29 & 10.21 & $Y=0.81+1.50 X$ & 0.32 \\
\hline Isabela & 1.69 & 55.88 & $Y=0.35+1.53 \mathrm{X}$ & 0.79 \\
\hline Palawan & 0.37 & 4.42 & $Y=0.93+2.15 X$ & 0.53 \\
\hline Davao del Norte & 0.18 & 10.07 & $Y=0.62+0.85 X$ & 0 \\
\hline
\end{tabular}

$\mathrm{X}^{2}$ values greater than 10 are not well represented by a line.

Table 1: Probit mortality data for alphacypermethrin tested against strains of An. flavirostris from the sentinel malarious provinces in the year 2001-2002.

Figure 3: Regression lines from alphacypermethrin baseline toxicity tests conducted on An. flavirostris from sentinel areas (2001-2002). 
Public Health Open Access

\begin{tabular}{|c|c|c|c|c|}
\hline Strains & $\mathrm{LC}_{50}\left(\mathrm{mg}-\mathrm{ai} / \mathrm{m}^{2}\right)$ & $\mathrm{LC}_{99}\left(\mathrm{mg}-\mathrm{ai} / \mathrm{m}^{2}\right)$ & Linear Equation/Slope & $\mathbf{X}^{2}$ \\
\hline Agusan del Sur & 0.17 & 1.72 & $Y=1.77+2.34 X$ & 0.70 \\
\hline Kalinga & 0.44 & 4.19 & $Y=0.85+2.36 X$ & 0.98 \\
\hline Isabela & 0.77 & 13.81 & $Y=0.21+1.85 X$ & 0.71 \\
\hline Palawan & 0.38 & 3.88 & $Y=0.96+2.31 X$ & 0.10 \\
\hline Davao del Norte & 0.39 & 13.28 & $Y=0.62+1.52 X$ & 0.04 \\
\hline
\end{tabular}

$\mathrm{X}^{2}$ values greater than 10 are not well represented by a line.

Table 2: Probit mortality data for deltamethrin tested against strains of An. flavirostris from the sentinel malarious provinces in the year 2001-2002.

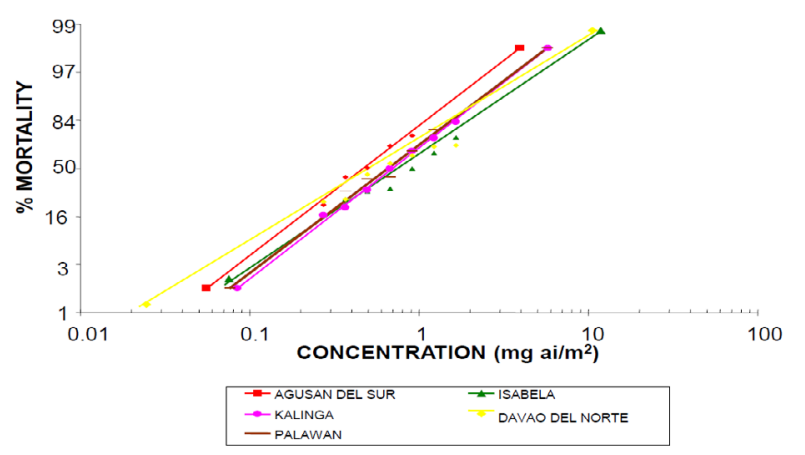

Figure 4: Regression lines from deltamethrin baseline toxicity tests conducted on An. flavirostris from sentinel areas (20012002).

Follow-up monitoring of An. flavirostris strains after one and a half years showed decreasing order of toxicities from alphacypermethrin based on computed $\mathrm{LC}_{50}$ : Kalinga < Davao del Norte and Palawan $<$ Agusan del Sur $<$ Occidental Mindoro < Isabela (Table 3). Kalinga strain appeared to be the most susceptible this time with Isabela strain the least susceptible as shown in regression lines (Figure 5). Based on $\mathrm{LC}_{99}$, the decreasing order of alphacypermethrin toxicity was: Davao del Norte $<$ Kalinga $<$ Occidental Mindoro $<$ Palawan $<$ Agusan del Sur $<$ Isabela.
Deltamethrin toxicity tests across An. flavirostris strains one and a half years after the baseline showed the following decreasing order based on $\mathrm{LC}_{50}$ : Isabela, Kalinga and Occidental Mindoro < Agusan del Sur $<$ Davao del Norte $<$ Palawan (Table 4). Based on $\mathrm{LC}_{99}$ the decreasing order of toxicity was as follows: Agusan del Sur $<$ Occidental Mindoro $<$ Davao del Norte < Kalinga < Palawan < Isabela. Steepest lines drawn from Davao del Norte and Occidental Mindoro indicated innate toxicity of deltamethrin to those strains (Figure 6).

\begin{tabular}{|c|c|c|c|c|}
\hline Strains & $\mathrm{LC}_{50}\left(\mathrm{mg}-\mathrm{ai} / \mathrm{m}^{2}\right)$ & $\mathrm{LC}_{99}\left(\mathrm{mg}-\mathrm{ai} / \mathrm{m}^{2}\right)$ & Linear Equation/Slope & $\mathbf{X}^{2}$ \\
\hline Agusan del Sur & 0.48 & 24.07 & $Y=0.43+1.93 X$ & 0.15 \\
\hline Kalinga & 0.18 & 2.93 & $Y=1.42+1.93 X$ & 0.66 \\
\hline Isabela & 0.95 & 62.82 & $Y=0.03+1.28 X$ & 0.34 \\
\hline Palawan & 0.29 & 4.02 & $Y=1.09+2.05 \mathrm{X}$ & 0.32 \\
\hline Occidental Mindoro & 0.49 & 3.38 & $Y=0.86+2.77 X$ & 0.29 \\
\hline Davao del Norte & 0.29 & 2.44 & $Y=1.34+2.53 \mathrm{X}$ & 0.97 \\
\hline
\end{tabular}

$\mathrm{X}^{2}$ values greater than 10 are not well represented by a line.

Table 3: Probit mortality data for alphacypermethrin tested against strains of An. flavirostris from the sentinel malarious provinces in the year 2004-2005. 


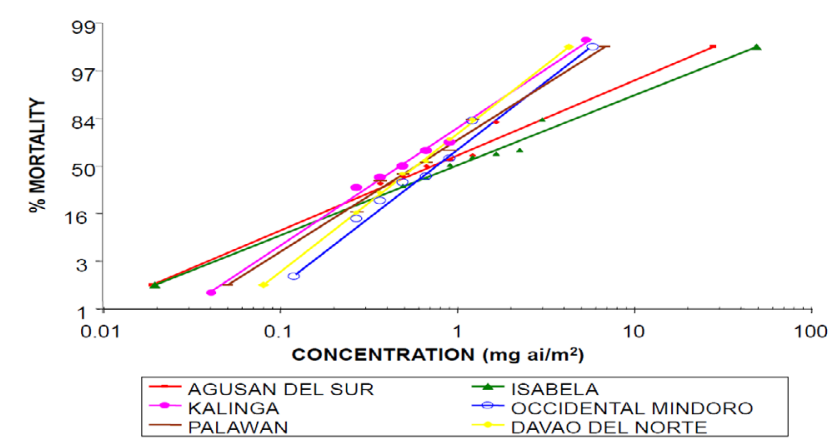

Figure 5: Alphacypermethrin regression lines from follow up monitoring of An. flavirostris from sentinel areas (2004-2005).

\begin{tabular}{|c|c|c|c|c|}
\hline Strains & $\mathrm{LC}_{50}\left(\mathrm{mg}-\mathrm{ai} / \mathrm{m}^{2}\right)$ & $\mathrm{LC}_{99}\left(\mathrm{mg}-\mathrm{ai} / \mathrm{m}^{2}\right)$ & Linear Equation/Slope & $\mathbf{X}^{2}$ \\
\hline Agusan del Sur & 0.17 & 1.72 & $Y=1.77+2.34 X$ & 0.70 \\
\hline Kalinga & 0.16 & 4.72 & $Y=1.26+1.59 X$ & 0.41 \\
\hline Isabela & 0.16 & 76.58 & $Y=0.67+0.77 X$ & 0.41 \\
\hline Palawan & 0.31 & 5.1 & $Y=0.98+1.90 X$ & 0.39 \\
\hline Occidental Mindoro & 0.16 & 2.22 & $Y=1.62+2.03 X$ & 0.38 \\
\hline Davao del Norte & 0.28 & 2.43 & $Y=1.37+2.49 X$ & 0.41 \\
\hline
\end{tabular}

$\mathrm{X}^{2}$ values greater than 10 are not well represented by a line.

Table 4: Probit mortality data for deltamethrin tested against strains of An. flavirostris from the sentinel malarious provinces in the year 2004-2005.

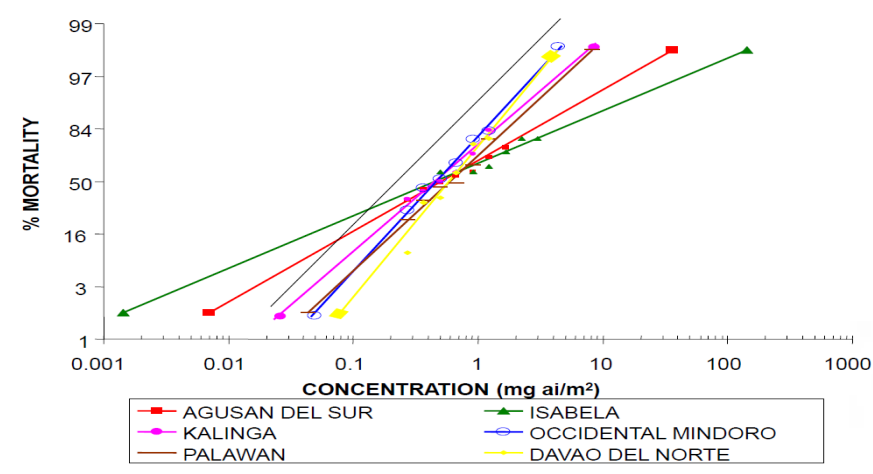

Figure 6: Deltamethrin regression lines from follow up monitoring of An. flavirostris from sentinel areas (2004-2005).

Use of Knockdown Time (KT) as a gauge of $A$. flavirostris strain susceptibilities

Table 5 shows a range of knockdown (65.33\%-100.00\%) after 1-hour exposure to each of the test insecticides. The graphs (regression lines) produced by plotting percent knockdown (every five minutes for an hour exposure) showed relative toxicities of each compound for each strain or population of An. flavirostris. The graph shows that $\mathrm{KT}_{50}$ and $\mathrm{KT}_{99}$ were unique characteristics of Anopheles strains and can be used to show trends in the development of resistance. Based on $\mathrm{KT}_{50}$ permethrin appeared the most toxic while alphacypermethrin appeared the least toxic to An. flavirostris Agusan del Sur population (Figure 7a). Using $\mathrm{KT}_{50}$ as indicator; cyfluthrin appeared the most toxic while etofenprox appeared the least toxic to An. flavirostris 
Palawan population (Figure 7b); etofenprox appeared the most toxic while alphacypermethrin appeared least toxic to An. flavirostris Isabela population (Figure 7c); cyfluthrin appeared the most toxic while alphacypermethrin appeared least toxic to An. flavirostris Davao del Norte population (Figure $7 \mathrm{~d}$ ); and permethrin appeared the most toxic while alphacypermethrin appeared least toxic to An. flavirostris Zamboanga Sibugay population (Figure 7e). These knockdown regression lines may serve as guide on how to choose compounds for the control of vectors in the area by looking at the levels of toxicity of the insecticides exhibited by knockdown.

\begin{tabular}{|c|c|c|c|c|c|c|c|c|}
\hline \multirow{2}{*}{ Strain } & \multicolumn{9}{|c|}{ Percent knockdown (\%) } \\
\cline { 2 - 10 } & ALP & DEL 0.01\% & DEL 0.05\% & CYF & ETO & LAM & PER & Control \\
\hline Agusan del Sur & 89.33 & 98.67 & 98.67 & 96 & 98.67 & 98.67 & 100 & 0 \\
\hline Davao del Norte & 78.67 & 74.67 & 97.33 & 98.67 & 97.33 & 98.67 & 98.67 & 0 \\
\hline Isabela & 65.33 & 82.67 & 97.33 & 94.67 & 98.67 & 94.67 & 81.33 & 1.33 \\
\hline Occidental Mindoro & 97.33 & 100 & 100 & 100 & 100 & 97.33 & 100 & 0 \\
\hline Palawan & 84 & 97.33 & 96 & 94.67 & 90.67 & 100 & 100 & 0 \\
\hline Zamboanga Sibugay & 69.33 & 74.67 & 90.67 & 78.67 & 97.33 & 80 & 93.33 & 0 \\
\hline
\end{tabular}

ALP: Alphacypermethrin 0.01\%; CYF: Cyfluthrin 0.15\%; DEL 0.01\%: Deltamethrin 0.01\%; DEL 0.05\%: Deltamethrin 0.05\%; ETO: Etofenprox 0.5\%; LAM: Lambdacyhalothrin 0.05\%; PER: Permethrin 0.75\%

Table 5: Anopheles flavirostris $(\mathrm{N}=75)$ knockdown responses after 1-hour exposure to discriminating concentrations

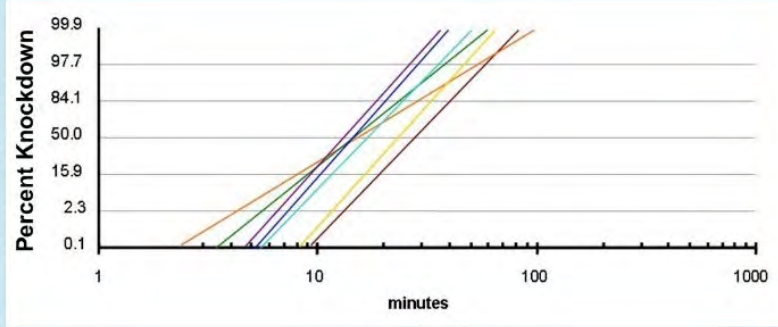

a

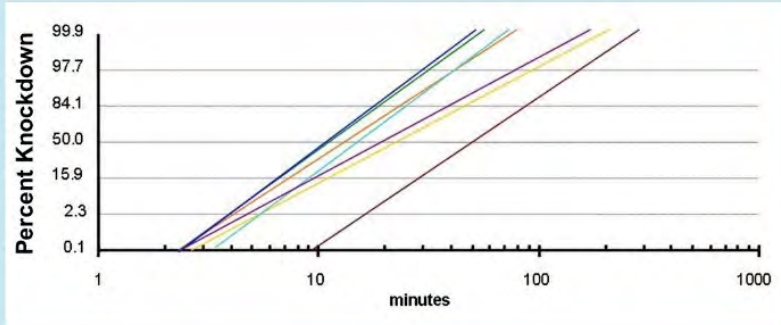

C

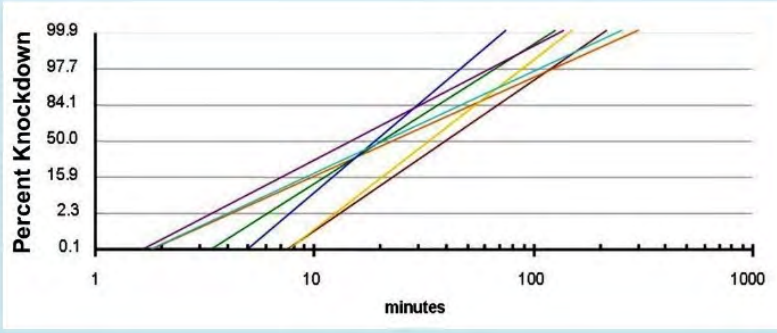

e

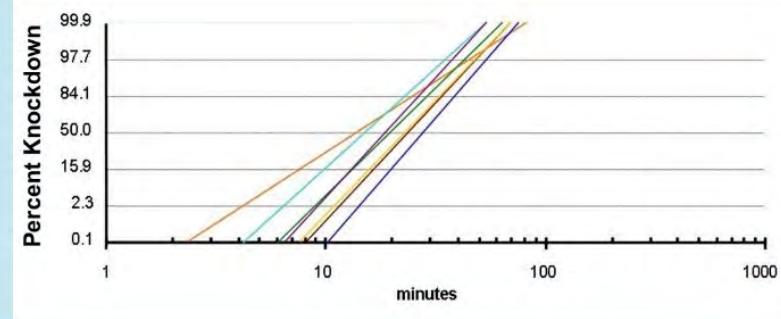

b

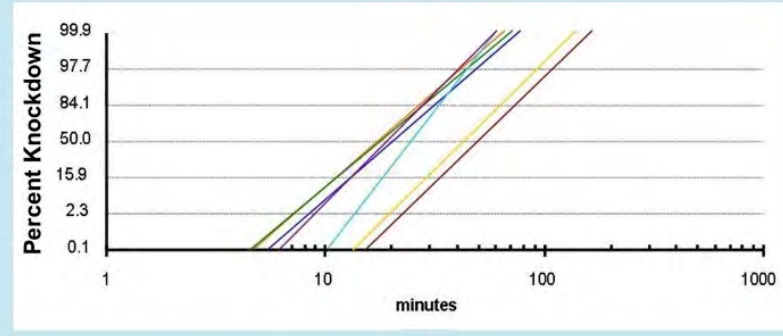

d

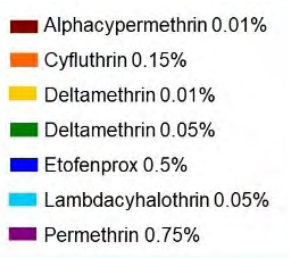

Figure 7: Knockdown regression lines resulting from exposure of An. flavirostris populations to insecticides discriminating concentrations; (a) Agusan del Sur, (b) Palawan, (c) Isabela, (d) Davao del Norte, (e) Zamboanga Sibugay 


\section{Resistance Monitoring in An. flavirostris Using WHO Diagnostic Concentrations}

Vector resistance assessments conducted from 2006 to 2013 followed the original WHO procedure with the use of 75 mosquitoes to consider a resistance test valid $[17,18]$. Following the revised insecticide susceptibility guidelines [24], at least 100 mosquitoes per insecticide diagnostic concentration was used in each of the succeeding tests conducted. In 2006, insecticide resistance monitoring using WHO discriminating concentrations was conducted from the sentinel provinces of Isabela, Occidental Mindoro, Palawan, Davao del Norte, Zamboanga Sibugay and Agusan del Sur. Anopheles flavirostris from these provinces showed full susceptibility (100\% mortality) to the following pyrethroids: permethrin, deltamethrin, etofenprox, cyfluthrin and lambdacyhalothrin (Table 6). Additional susceptibility monitoring was done using the locally-determined discriminating doses for alphacypermethrin $(0.01 \%)$ and deltamethrin $(0.01 \%)$ wherein full susceptibilities $(100 \%$ test mortality) of An. flavirostris were also observed (Table 7).

In 2007, susceptibility tests were conducted from the northern provinces of Kalinga and Isabela. Anopheles flavirostris population from Tabuk, Kalinga showed susceptibility to deltamethrin, resistance to etofenprox and lambdacyhalothrin and incipient resistance to permethrin. Full An. flavirostris susceptibility (100\% mortality) was observed to permethrin and deltamethrin from San Mariano, Isabela but showed incipient resistance status to etofenprox and lambdacyhalothrin needing further verification. In 2010, the provinces of Davao Region (Davao del Norte and Davao Oriental) were visited for vector resistance assessment. Anopheles flavirostris collected from Kapalong, Davao del Norte showed full susceptibility to the test organophosphorus compound malathion but was noted resistant towards permethrin and showed incipient resistance towards deltamethrin and DDT. On the other hand, An. flavirostris samples from Mati City, Davao Oriental showed full susceptibility to permethrin, deltamethrin, malathion and DDT.

In 2011, malaria vectors from the representative northern provinces of Kalinga, Mt. Province and Isabela and the island of Palawan were assessed. Anopheles flavirostris population from Pinukpuk, Kalinga showed complete susceptibility to deltamethrin and malathion while mortality of $95.6 \%$ and $97.8 \%$ from permethrin and DDT respectively. However, further tests conducted in 2013 were recoreded, Pinukpuk strain's susceptibility to permethrin and DDT. Tests ensued full susceptibility of An. flavirostris Mt. Province strain to deltamethrin. Anopheles flavirostris population from Isabela showed full susceptibility to permethrin and deltamethrin while incipient resistance status was recorded for both lambdacyhalothrin and DDT (93.3\% mortality). Subsequent tests conducted in 2013 showed susceptibility of An. flavirostris Isabela strain to both lambdacyhalothrin and DDT. Tests conducted for An. flavirostris population from Puerto Princesa, Palawan showed full susceptibility to all the test compounds permethrin, deltamethrin, lambdacyhalothrin and DDT.

In 2013, the resistance tests revealed full susceptibilities of An. flavirostris from the provinces of Kalinga, Isabela, Palawan, Davao Oriental and Agusan del Sur against the six test insecticides: permethrin, deltamethrin, cyfluthrin, lambdacyhalothrin, etofenprox and DDT. In the same year, $A n$. flavirostris from Occidental Mindoro showed susceptibility to permethrin, deltamethrin and etofenprox while lambdacyhalothrin tests resulted in $89.3 \%$ test mortality indicative of resistance. In 2015, the island of Camiguin was visited and tests showed that $A n$. flavirostris population from the island has full susceptibility to permethrin, etofenprox, malathion and DDT insecticides while deltamethrin test yielded incipient resistance level ( $97.3 \%$ mortality) needing further confirmation. In the same year, tests conducted in Davao Oriental province showed full susceptibility of $A n$. flavirostris population from Generoso against etofenprox and from Mati City against permethrin. Complete susceptibilities were recorded from pyrethroids (permethrin, deltamethrin, cyfluthrin, lambdacyhalothrin and etofenprox) and organophosphorus compound (malathion) tests on An. flavirostris from Quirino province. Tests in the provinces of Ilocos Norte, Palawan and Sultan Kudarat also recorded etofenprox-susceptible An. flavirostris from those areas.

In 2016, An. flavirostris populations from the northern province of Cagayan showed full susceptibility to permethrin, deltamethrin, etofenprox, lambdacyhalothrin and alphacypermethrin. Anopheles flavirostris from the nearby province of Nueva Vizcaya also showed full susceptibility to permethrin and etofenprox. In 2017, tests were only conducted in Puerto Princesa, Palawan showing full susceptibility of An. flavirostris to deltamethrin and etofenprox diagnostic concentrations. Test conducted in Esperanza, Agusan del Sur and Bulalacao, Oriental Mindoro in 2018 showed susceptibility of An. flavirostris population to permethrin. Intensified susceptibility monitoring was conducted in the island of Palawan in the same year. Tests conducted in Puerto Princesa City revealed full susceptibility of An. flavirostris to pyrethroids (permethrin, deltamethrin, cyfluthrin, lambdacyhalothrin and etofenprox), organophosphates (malathion and fenitrothion), carbamates (propoxur and bendiocarb) and the organochlorine compound DDT. Anopheles flavirostris populations from the municipality of Quezon revealed full susceptibility to permethrin, deltamethrin, etofenprox, lambdacyhalothrin 
and DDT. Tests conducted in Rizal, Palawan ensued full susceptibility of An. flavirostris to permethrin, deltamethrin, etofenprox, malathion, fenitrothion, propoxur, bendiocarb and DDT. However, confirmatory tests are needed to ascertain An. flavirostris Rizal, Palawan strain's incipient resistance status against the pyrethroids cyfluthrin $(94.6 \%$ test mortality) and lambdacyhalothrin (93.3\% test mortality). In 2019, additional susceptibility tests showed An. flavirostris Rizal strain maintaining its susceptibility to permethrin, deltamethrin and etofenprox. Incipient resistant status of An. flavirostris were noted from the following sites (Table 7): Tabuk, Kalinga towards permethrin (in 2007); Kapalong, Davao del Norte towards deltamethrin and DDT (in 2010); Guinsiliban, Camiguin towards deltamethrin (in 2015) and Rizal, Palawan towards cyfluthrin and lambdacyhalothrin (in 2018). Ideally, follow-up monitoring should result to confirmatory resistance status, however this was not the case in field situations.

\begin{tabular}{|c|c|c|c|c|c|c|c|c|c|c|c|c|c|}
\hline \multicolumn{2}{|c|}{ Collection Site } & \multirow[b]{2}{*}{ Year } & \multicolumn{6}{|c|}{ Pyrethroids } & \multicolumn{2}{|c|}{ OP } & \multicolumn{2}{|c|}{ Carbamate } & \multirow{2}{*}{$\begin{array}{c}\text { OC } \\
\text { DDT }\end{array}$} \\
\hline Region & $\begin{array}{c}\text { City/ } \\
\text { Municipality, } \\
\text { Province }\end{array}$ & & PER & DEL & ETO & CYF & LAM & ALP & MAL & FEN & PRO & BEN & \\
\hline \multirow{4}{*}{$\begin{array}{c}\text { Cordillera } \\
\text { Administrative } \\
\text { Region (CAR) }\end{array}$} & \multirow{2}{*}{ Pinukpuk, Kalinga } & 2011 & 95.6 & 100 & & & & & 100 & & & & 97.8 \\
\hline & & 2013 & 100 & 100 & 100 & 100 & 100 & & & & & & 100 \\
\hline & $\begin{array}{l}\text { Tabuk City, } \\
\text { Kalinga }\end{array}$ & 2007 & 95.7 & 98.6 & 88.9 & & 74.6 & & & & & & \\
\hline & Paracelis, Kalinga & 2011 & & 100 & & & & & & & & & \\
\hline $\begin{array}{l}\text { I (Ilocos } \\
\text { Region) }\end{array}$ & $\begin{array}{l}\text { Pagudpud, Ilocos } \\
\text { Norte }\end{array}$ & 2015 & & & 100 & & & & & & & & \\
\hline \multirow{7}{*}{$\begin{array}{l}\text { II (Cagayan } \\
\text { Valley) }\end{array}$} & $\begin{array}{l}\text { Allacapan, } \\
\text { Cagayan }\end{array}$ & 2016 & 100 & 100 & 100 & & 100 & 100 & & & & & \\
\hline & \multirow{4}{*}{$\begin{array}{l}\text { San Mariano, } \\
\text { Isabela }\end{array}$} & 2006 & 100 & 100 & 100 & 100 & 100 & & & & & & \\
\hline & & 2007 & 100 & 100 & 96 & & 96 & & & & & & \\
\hline & & 2011 & 100 & 100 & & & 93.3 & & & & & & 93.3 \\
\hline & & 2013 & 100 & 100 & 98.7 & 100 & 100 & & & & & & 100 \\
\hline & $\begin{array}{l}\text { Dupax del Norte, } \\
\text { Nueva Vizcaya }\end{array}$ & 2016 & 100 & & 100 & & & & & & & & \\
\hline & Diffun, Quirino & 2015 & 100 & 100 & 100 & 100 & 100 & & 100 & & & & \\
\hline \multirow{12}{*}{$\begin{array}{c}\text { IV-B } \\
\text { (Mimaropa) }\end{array}$} & \multirow{2}{*}{$\begin{array}{c}\text { Paluan, Occidental } \\
\text { Mindoro }\end{array}$} & 2006 & 100 & 100 & 100 & 100 & 100 & & & & & & \\
\hline & & 2013 & 98.7 & 100 & 100 & & 89.3 & & & & & & \\
\hline & $\begin{array}{c}\text { Bulalacao, } \\
\text { Oriental Mindoro }\end{array}$ & 2018 & 100 & & & & & & & & & & \\
\hline & \multirow{4}{*}{$\begin{array}{l}\text { Puerto Princesa } \\
\text { City, Palawan }\end{array}$} & 2011 & 100 & 100 & & & 100 & & & & & & 100 \\
\hline & & 2015 & & & 100 & & & & & & & & \\
\hline & & 2017 & & 100 & 100 & & & & & & & & \\
\hline & & 2018 & 99 & 100 & 100 & 98.9 & 99 & & 100 & 100 & 100 & 100 & 100 \\
\hline & \multirow{3}{*}{ Quezon, Palawan } & 2006 & 100 & 100 & 100 & 100 & 100 & & & & & & \\
\hline & & 2013 & 100 & 100 & 100 & 100 & 100 & & & & & & 100 \\
\hline & & 2018 & 100 & 100 & 100 & & 100 & & & & & & 100 \\
\hline & \multirow[t]{2}{*}{ Rizal, Palawan } & 2018 & 100 & 100 & 100 & 94.6 & 93.3 & & 100 & 100 & 100 & 100 & 100 \\
\hline & & 2019 & 100 & 100 & 100 & & & & & & & & \\
\hline $\begin{array}{c}\text { IX } \\
\text { (Zamboanga } \\
\text { Peninsula) }\end{array}$ & $\begin{array}{c}\text { Tungawan, } \\
\text { Zamboanga } \\
\text { Sibugay }\end{array}$ & 2006 & 100 & 100 & 100 & 100 & 100 & & & & & & \\
\hline
\end{tabular}




\begin{tabular}{|c|c|c|c|c|c|c|c|c|c|}
\hline $\begin{array}{c}\text { X (Northern } \\
\text { Mindanao) }\end{array}$ & $\begin{array}{l}\text { Guinsiliban, } \\
\text { Camiguin }\end{array}$ & 2015 & 100 & 97.3 & 100 & & & 100 & 100 \\
\hline \multirow{6}{*}{$\begin{array}{c}\text { XI (Davao } \\
\text { Region) }\end{array}$} & \multirow{2}{*}{$\begin{array}{c}\text { Kapalong, Davao } \\
\text { del Norte }\end{array}$} & 2006 & 100 & 100 & 100 & 100 & 100 & & \\
\hline & & 2010 & 87.5 & 93.6 & & & & 100 & 95 \\
\hline & $\begin{array}{l}\text { Gov. Generoso, } \\
\text { Davao Oriental }\end{array}$ & 2015 & & & 100 & & & & \\
\hline & \multirow{3}{*}{$\begin{array}{c}\text { Mati City, Davao } \\
\text { Oriental }\end{array}$} & 2010 & 98.8 & 98.8 & & & & 100 & 100 \\
\hline & & 2013 & 99 & 100 & 100 & 100 & 99.1 & & 100 \\
\hline & & 2015 & 100 & & & & & & \\
\hline $\begin{array}{c}\text { XII } \\
\text { (Soccsksargen } \\
\text { Region) }\end{array}$ & $\begin{array}{c}\text { Lebak, Sultan } \\
\text { Kudarat }\end{array}$ & 2015 & & & 100 & & & & \\
\hline \multirow{3}{*}{$\begin{array}{l}\text { XIII (Caraga } \\
\text { Region) }\end{array}$} & \multirow{2}{*}{$\begin{array}{l}\text { Bayugan City, } \\
\text { Agusan del Sur }\end{array}$} & 2006 & 100 & 100 & 100 & 100 & 100 & & \\
\hline & & 2013 & 100 & 100 & 100 & 100 & 100 & & 100 \\
\hline & $\begin{array}{c}\text { Esperanza, } \\
\text { Agusan del Sur }\end{array}$ & 2018 & 100 & & & & & & \\
\hline
\end{tabular}

ALP: Alphacypermethrin 0.05\%; BEN: Bendiocarb 0.1\%; CYF: Cyfluthrin 0.15\%; DDT: DDT 4\%; DEL: Deltamethrin 0.05\%; ETO: Etofenprox 0.5\%; FEN: Fenitrothion 1\%; LAM: Lambdacyhalothrin 0.05\%; MAL: Malathion 5\%; OC: Organochlorine; OP: Organophosphates; PER: Permethrin 0.75\%; PRO: Propoxur 0.1\%

Table 6: Mortality rates (\%) of An. flavirostris after exposure to each insecticide at diagnostic doses (2006-2019)

\begin{tabular}{|c|c|c|c|}
\hline Region & City/Municipality, Province & $\begin{array}{c}\text { Alphacypermethrin } \\
\left(3.06 \mathrm{mg} \mathrm{ai} / \mathrm{m}^{2} \sim 0.01 \%\right)\end{array}$ & $\begin{array}{c}\text { Deltamethrin (3.66mg } \\
\left.\text { ai } / \mathrm{m}^{2} \sim 0.01 \%\right)\end{array}$ \\
\hline II (Cagayan Valley) & San Mariano, Isabela & 100 & 100 \\
\hline IV-B (Mimaropa) & Paluan, Occidental Mindoro & 100 & 100 \\
\hline IX (Zamboanga Peninsula) & Tungawan, Zamboanga Sibugay & 100 & 100 \\
\hline XI (Davao Region) & Kapalong, Davao del Norte & 100 & 100 \\
\hline XIII (Caraga Region) & Bayugan City, Agusan del Sur & 100 & 100 \\
\hline
\end{tabular}

Table 7: Mortality rates (\%) of An. flavirostris after exposure to locally-determined discriminating doses of alphacypermethrin and deltamethrin (2006)

\section{Susceptibility Monitoring with Secondary Vectors}

Limited susceptibility tests were carried out on $A n$. maculatus s.l. from 2011 to 2015. Insecticide resistance monitoring ensued full susceptibility of the secondary vector from Paracelis, Mt. Province and Puerto Princesa City, Palawan to permethrin, deltamethrin, lambdacyhalothrin and DDT compounds in 2011 (Table 8). Likewise, full susceptibility was also noted in An. maculatus s.l. from San Mariano, Isabela against permethrin and DDT in the same year. In 2013, populations from Paluan, Occidental Mindoro revealed full susceptibility to permethrin, deltamethrin and etofenprox, incipient resistance to cyfluthrin and DDT (92\% and $94.7 \%$ test mortality, respectively) and resistance to lambdacyhalothrin $(85.8 \%$ mortality $)$. In
2015, full susceptibility to deltamethrin was noted from An. maculatus s.l. population from Subic, Zambales while incipient resistance to etofenprox was recorded from Diffun, Quirino populations. In the same year, full susceptibility to etofenprox of An. maculatus s.l. populations from Bataraza and Puerto Princesa in Palawan province was recorded however incipient resistance to permethrin was noted in Puerto Princesa strain. Populations of brackish water breeding An. litoralis were collected from the provinces of Camarines Norte and Samar. The 2015 assessment revealed An. litoralis Paracale, Camarines Norte strain's incipient resistance to permethrin (Table 9). The visit to Marabut, Samar in 2016 revealed full susceptibility of An. litoralis to permethrin and DDT while incipient resistance was noted towards malathion. 


\begin{tabular}{|c|c|c|c|c|c|c|c|c|}
\hline \multicolumn{2}{|c|}{ Collection Site } & \multirow[b]{2}{*}{ Year } & \multicolumn{5}{|c|}{ Pyrethroids } & \multirow{2}{*}{$\begin{array}{c}\text { OC } \\
\text { DDT }\end{array}$} \\
\hline Region & $\begin{array}{l}\text { City/ Municipality, } \\
\text { Province }\end{array}$ & & PER & DEL & ETO & CYF & LAM & \\
\hline $\begin{array}{l}\text { Cordillera Administrative } \\
\text { Region (CAR) }\end{array}$ & Paracelis, Mt. Province & 2011 & 100 & 100 & & & 100 & 100 \\
\hline \multirow{2}{*}{ I (Cagayan Valley) } & San Mariano, Isabela & 2011 & 100 & & & & & 100 \\
\hline & Diffun, Quirino & 2015 & & & 96.7 & & & \\
\hline III (Central Luzon) & Subic, Zambales & 2015 & & 100 & & & & \\
\hline \multirow{4}{*}{ IV-B (Mimaropa) } & $\begin{array}{l}\text { Paluan, Occidental } \\
\text { Mindoro }\end{array}$ & 2013 & 98.7 & 100 & 100 & 92 & 85.8 & 94.7 \\
\hline & Bataraza, Palawan & 2015 & & & 100 & & & \\
\hline & \multirow{2}{*}{$\begin{array}{c}\text { Puerto Princesa City, } \\
\text { Palawan }\end{array}$} & 2011 & 100 & 100 & & & 100 & 100 \\
\hline & & 2015 & 96.9 & & 100 & & & \\
\hline
\end{tabular}

CYF: Cyfluthrin 0.15\%; DDT: DDT 4\%; DEL: Deltamethrin 0.05\%; ETO: Etofenprox 0.5\%; LAM: Lambdacyhalothrin 0.05\%; OC: Organochlorine; PER: Permethrin $0.75 \%$

Table 8: Mortality rates (\%) of An. maculatus s.l. after exposure to each insecticide at diagnostic doses (2011-2015)

\begin{tabular}{|c|c|c|c|c|c|}
\hline \multicolumn{2}{|r|}{ Collection Site } & \multirow{2}{*}{ Year } & \multirow{2}{*}{$\begin{array}{c}\text { Pyrethroid } \\
\text { PER }\end{array}$} & \multirow{2}{*}{$\begin{array}{c}\text { Organophosphate } \\
\text { MAL }\end{array}$} & \multirow{2}{*}{$\begin{array}{c}\text { Organochlorine } \\
\text { DDT }\end{array}$} \\
\hline Region & City/ Municipality, Province & & & & \\
\hline V (Bicol Region) & Paracale, Camarines Norte & 2015 & 95.7 & & \\
\hline $\begin{array}{l}\text { VIII (Eastern } \\
\text { Visayas) }\end{array}$ & Marabut, Samar & 2016 & 100 & 95 & 100 \\
\hline
\end{tabular}

DDT: DDT4\%; MAL: Malathion 5\%; PER: Permethrin 0.75\%

Table 9: Mortality rates of An. litoralis after exposure to each insecticide at diagnostic doses (2015-2016)

\section{Discussion}

\section{Establishment of Discriminating Doses for Local Vectors}

Dose response assays were conducted to establish local discriminating doses for the primary malaria vector, An. flavirostris. Established local discriminating doses per insecticide per vector species is ideal to concretely follow reduction in vector's susceptibility as well as the development of tolerance and/or resistance of a species to a compound. Baseline data and follow-up monitoring tests showed high toxicity of alphacypermethrin and deltamethrin to An. flavirostris from the provinces of Kalinga, Palawan, Occidental Mindoro, Davao del Norte and Agusan del Sur. The resulting lethal concentration provided insecticide amounts that causes mortality as exemplified by the regression line produced in each strain (Figure 7). Baseline data for alphacypermethrin and deltamethrin showed the Agusan del Sur strain to be the most susceptible strain amongst the representative of the sentinel sites. This susceptibility could be attributed to minimal insecticide pressure received by the strain in previous years. Based on the 1999 situational analysis done by RITM, very minimal insecticide-based vector control interventions (ex. indoor residual spraying and insecticide-treated nets) were implemented [14].
Based on the earlier visits conducted in the area, the people (consisting mainly of indigenous Manobos) were observed to practice underdeveloped agricultural technologies with minimal use of insecticides. After the one and a half years that followed, significant decrease in the susceptibility levels of Agusan Del Sur strain of An. flavirostris were noted based on the $\mathrm{LC}_{50}$ values (Tables $3 \& 4$ ). The dose response assessments ensued discriminating doses (twice $\mathrm{LC}_{99}$ ) of $3.06 \mathrm{mg} \mathrm{ai} / \mathrm{m}^{2}$ for alphacypermethrin and $3.66 \mathrm{mg} \mathrm{ai} / \mathrm{m}^{2}$ for deltamethrin. Using the standard conversion factor $[1 \%$ $=343 \mathrm{mg}$ active ingredient $\left.(a \mathrm{i}) / \mathrm{m}^{2}\right]$, the discriminating doses equates to $0.01 \%$ for both alphacypermethrin and deltamethrin. The WHO recommended discriminating doses for alphacypermethrin and deltamethrin is $0.05 \%$ which were five times higher than the computed dose for the local vector An. flavirostris, again indicating high susceptibility of the strain.

From the attempts to establish discriminating dose for local vectors using dose response method, advantages were noted including the capacity to determine the amount of active ingredient (concentration) needed to kill each of the local strains that have provided concrete documentation of resistance evolution (Tables 1,2 \& Figures 3,4 ). The resistance monitoring done in 2006 using the locally-established discriminating concentrations showed that An. flavirostris 


\section{Public Health Open Access}

strains from the sentinel sites (Isabela, Occidental Mindoro, Palawan, Zamboanga Sibugay, Davao del Norte and Agusan del Sur) remained fully susceptible $(100 \%$ mortality) for about four years [25]. Limitations were encountered in the implementation of dose response assay. First, it takes a long time to establish discriminating doses even for just the two test insecticides. Dose response approach also needed more manpower and time to spend per insecticide; i.e. bracketing for two insecticides equals the time and resources spent to determine susceptibilities of 5-6 different insecticides using WHO's discriminating or diagnostic concentrations. Several concentrations (4-5 concentrations) were needed to generate mortality data ranging from $5-100 \%$. Furthermore, purchase of insecticide concentrations which do not belong to WHO's list for monitoring resistance costed more and it took longer time to be delivered.

The knockdown recording approach showed trends in relative insecticide toxicity for each site. Although similar diagnostic concentrations were used to arrive at knockdown time, there is a need for careful observation and trained personnel to record certainly knockdown every five minutes. Several other limitations include large numbers of malaria vectors to complete assays, which also meant more time needed to collect vectors from sentinel sites and more staff to observe knockdown at specified intervals. Both dose response and knockdown approaches had been laborintensive and more costly.

\section{WHO Discriminating Concentrations}

The data on malaria vectors' susceptibility using the WHO discriminating concentrations allowed comparison of the resistance levels of vectors around the world. The magnitude and prevalence of resistance reported in Africa [26-28], in the Americas [29] and in Asia [30,31] were in general far advanced compared to very high susceptibility exhibited by the local vectors to the WHO recommended and tested insecticides. The monitoring of insecticide resistance using the WHO diagnostic dose also provided faster generation of susceptibility results and conduct susceptibility evaluations in more areas among insecticides used in the control interventions. This provided the public health authorities basis of resistance in vectors so that a corresponding change in policy for insecticide use could be made locally. While most An. flavirostris populations remained fully susceptible to the insecticides tested, resistance was recorded in some areas (Figure 8). Incipient resistance in An. flavirostris was also noted to pyrethroids and DDT in several areas. The absence of regular budgetary allocations for insecticide resistance monitoring and of local personnel to accompany the monitoring team to conduct the activities in the field limited the schedule of needed verification visits in places with incipient resistance status. Delays in the procurement of WHO impregnated papers also led to cancellation of scheduled activities.

Even though earlier tests noted incipient resistance in some areas, subsequent monitoring tests showed $A n$. flavirostris' susceptibility. These findings may indicate presence of susceptible buffer populations of malaria vectors from different malarious localities. Since malaria in the Philippines still occurs in pristine areas, reversal of resistance can occur by allowing time for resistant populations to become diluted with insecticide-susceptible individuals. However, the time to revert back a resistant to susceptible mosquito population remains unknown. The best practice is still to reduce the chance of resistance development which can either be through the judicious use of insecticides, use of different active ingredients (ai) between complementary interventions (i.e. $a i$ for LLIN is different from ai for IRS), mosaic insecticide application following Insecticide Resistance Action Committee (IRAC) and WHO guidelines, rotation of insecticides and/or the use of mixed active ingredients as options [22,32].

In case resistance is developed, alternative insecticides (based on the results) having different mode of action are available. These alternatives belong to non-pyrethroid groups organophosphates (malathion, fenitrothion) and carbamates (bendiocarb, propoxur) to retard development of resistance. Further studies are needed to determine actual causes of resistance and mechanisms among the local vectors. Among the probable factors contributing to the development of resistance would be vector control practices; especially the scaled-up interventions using LLINs and IRS that led to elimination of malaria in most of the provinces in the country. Insecticide drifts from agricultural production may also have contributed to the selection pressure. Documentations from an informal survey conducted with farmers within the collection sites (Kalinga and Isabela provinces) in 2004-2005 showed that same pyrethroid compounds (i.e. with similar active ingredients) that were used for public health purposes were also used for rice, corn and vegetable productions (RITM, unpublished data).

Malaria transmission remains to exist in far-flung areas not affected by pollution and urbanization. Continuous monitoring and more intensified sampling of An. flavirostris strains however should be made to ascertain that susceptible status is maintained. The early shift in the compounds used for IRS and LLIN may be considered to prevent and retard resistance development before more complications result to the failure of intervention. In areas where resistance is documented, testing of alternative insecticides with different mode of action should continue. Further studies to characterize resistance mechanisms should be planned to understand future needs and their implications to malaria 
control, elimination, reintroduction and re-establishment. Documentation report of insecticide resistance monitoring in Bongao, Tawi-tawi revealed An. litoralis' full susceptibility to deltamethrin and pirimiphos-methyl compounds and incipient resistance status to permethrin, alphacypermethrin and etofenprox [15]. No further tests to ascertain status were done due to risks from political conflict. In this continuing resistance assessments, further resistance monitoring is urgently needed especially in areas with incipient resistance status. No resistance monitoring data were generated on other malaria vector species (An. balabacensis and An. mangyanus) due to the insufficient numbers of vectors collected to perform susceptibility test and the difficulty in transporting and growing them in the laboratory. These however should not set the attitude of neglecting these other vectors. Focus should still be given on their presence during monitoring collections and their relative numbers that may allow the conduct of the said tests. Laboratory colonization was earlier endeavored, but the species fragility and inability to mate naturally made colonization attempts fail. Urgent attention however, should be given to the possibility of the development of behavioral resistance (avoidance) on the local vectors. Anopheles flavirostris along with other vectors has been recently observed to be more exophilic and exophagic in behavior as witnessed most recently in the island of Palawan where malaria transmission remains high (RITM, unpublished data).

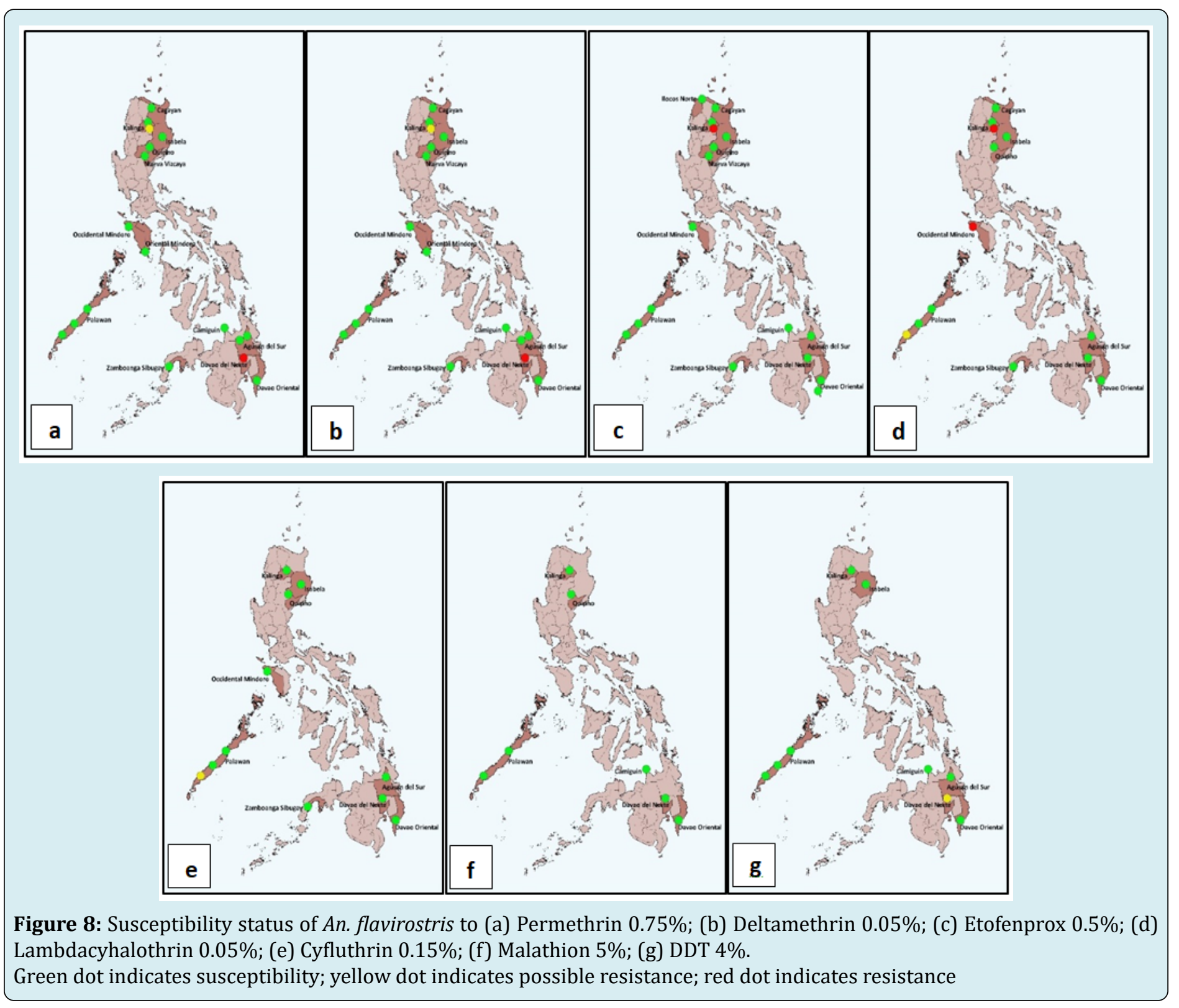




\section{Conclusion}

The study allowed exploration of ways to monitor trends in insecticide susceptibilities across malarious areas amongst the primary vector An. flavirostris and to limited extent An. maculatus s.l. and An. litoralis. The three methods used were able to show trends of resistance development. Dose response assays and use of knockdown time allowed further differentiation of the relative toxicities of insecticides to a particular malaria vector strain, an advantage in choosing the most toxic active ingredient, a major consideration in screening which insecticide to prioritize to use for vector control interventions. Dose response assay further provided exact doses to cause full mortality in the strains. Given those advantages, there are however inherent difficulties in conducting the monitoring process. The adoption of the WHO standard bioassay procedure successfully ensued discrimination in the susceptibility and resistance levels of different populations of An. flavirostris, An. maculatus s.l. and An. litoralis. Results showed susceptibilities of malaria vectors in the Philippines however recorded their ability to develop resistance in some areas. Beyond insecticide resistance, the greatest challenge seen is the probability of change in vector behavior as exhibited by An. flavirostris Palawan strains. Continuous monitoring of insecticide resistance and further vector behavior studies should be the major pathways forward to sustain the gains in the elimination, to prevent reintroduction and re-establishment of malaria in provinces declared free of the disease.

\section{Conflict of Interest}

The authors declare that they have no conflict of interests.

\section{References}

1. WHO (2020) World Malaria Report 2020, World Health Organization.

2. (2021) DOH, Partners Firm on Its Target to Reach Zero Malaria Case by 2030. Department of Health.

3. Foley DH, Torres EP, Mueller I, Bryan JH, Bell D (2003) Host-dependent Anopheles flavirostris larval distribution reinforces the risk of malaria near water. Trans $\mathrm{R}$ Soc Trop Med Hyg 97(3): 283-287.

4. Foley DH, Torres EP, Mueller I (2002) Stream-bank shade and larval distribution of the Philippine malaria vector Anopheles flavirostris. Med Vet Entomol 16(4): 347-355.

5. Catangui FP, Valera CV, Cabrera BD (1985) Vectors of malaria in the Philippines. Southeast Asian J Trop Med Public Health 16(1): 139-140.
6. WHO (2019) Guidelines for Malaria Vector Control. World Health Organization, pp: 138.

7. DOH-NMCEP (2020) National Strategic Plan for the Control and Elimination of Malaria in the Philippines 2020-2022.

8. Torres EP, Salazar NP, Belizario VY, Saul A (1997) Vector abundance and behaviour in an area of low malaria endemicity in Bataan, the Philippines. Acta Trop 63(4): 209-220.

9. Chow CY (1959) The Appearance of Dieldrin-Resistance in Anopheles minimus flavirostris in the Philippines. World Health Organization.

10. Salazar FV (2006) Insecticides resistance monitoring and management in agriculture and public health. Adalla C, et al. (Eds.), In Judicious Use of Insecticides: Bridging the gap between agriculture and public health in the Philippines. Manila: ACT Malaria, pp: 123-143.

11. Bautista A (1999) Health Science and Technology Priorities (1999-2004). Philippine Council for Health Research and Development, pp: 1-21.

12. Acuin J, Javellana J, Lopez N (1999) Health Science and Technology Priorities (1999-2004). Philippine Council for Health Research and Development, pp: 1-81.

13. Enoveso O (1999) Health Science and Technology Priorities (1999-2004). Philippine Council for Health Research and Development, pp: 1-22.

14. Hii J, Simpson G (2012) Evaluation of the Agusan Del Sur Malaria Control and Prevention Project Community Trust Fund, pp: 68.

15. Salazar FV, Torno MM, Galang C, Baquilod M, Bangs MJ (2015) Bionomics and ecology of Anopheles litoralis on Bongao Island, tawi-tawi province, Philippines: implications for vector control. Southeast Asian J Trop Med Public Health 46(3): 406-424.

16. Cagampang Ramos A, Darsie RFJ (1970) Illustrated keys to the Anopheles mosquitoes of the Philippine Islands. USAF Fifth Epidemiological Flight, PACAF, pp: 1-49.

17. WHO (1981) Criteria and meaning of tests for determining the susceptibility or resistance of insects to insecticides. World Health Organization, Geneva, pp: 1-4.

18. WHO (1998) Test procedures for insecticide resistance monitoring in malaria vectors, bio-efficacy \& persistence of insecticide on treated surfaces. World Health Organization, Geneva pp: 28-30. 
19. WHO (2016) Test procedures for insecticide resistance monitoring in malaria vector mosquitoes. $2^{\text {nd }}$ (Edn.), World Health Organization, pp: 1-48.

20. Remon C, Lobbia P, Zerba E, Mougabure Cueto G (2017) A methodology based on insecticide impregnated filter paper for monitoring resistance to deltamethrin in Triatoma infestans field populations. Med Vet Entomol 31(4): 414-426.

21. Sakuma M (1998) Probit analysis of preference data. Appl Entomol Zool 33(3): 339-347.

22. WHO (2012) Global plan for Insecticide Resistance Management In Malaria Vectors. World Health Organization.

23. Finney DJ (1971) Probit Analysis. $3^{\text {rd }}$ (Edn.), Cambridge: Cambridge University Press, UK.

24. WHO (2013) Test procedures for insecticide resistance monitoring in malaria vector mosquitoes. World Health Organization, pp: 30.

25. WHO (2010) The technical basis for coordinated action against insecticide resistance: preserving the effectiveness of modern malaria vector control Draft Meeting Report. World Health Organization, Geneva, pp: 1-36.

26. Knox TB, Juma EO, Ochomo EO, Jamet HP, Ndungo L, et al.
(2014) An online tool for mapping insecticide resistance in major Anopheles vectors of human malaria parasites and review of resistance status for the Afrotropical region. Parasit Vectors 7: 76.

27. Coleman M, Hemingway J, Gleave KA, Wiebe A, Gething PW, et al. (2017) Developing global maps of insecticide resistance risk to improve vector control. Malar J 16(1): 86.

28. Moyes CL, Athinya DK, Seethaler T, Battle KE, Sinka M, et al. (2020) Evaluating insecticide resistance across African districts to aid malaria control decisions. Proc Natl Acad Sci USA 117(36): 22042-22050.

29. Riveron JM, Tchouakui M, Mugenzi L, Menze BD, Mu Chun C, et al. (2018) Insecticide Resistance in Malaria Vectors: An Update at a Global Scale. Intech Open, pp: 149-175.

30. Khan N, Mishra AK, Das A (2020) Insecticide resistance in Indian Anopheles: A stumbling block for malaria elimination. Asian Pac J Trop Med 13(10): 429-430.

31. WHO (2018) Global report on insecticide resistance in malaria vectors: 2010-2016. World Health Organization, Geneva.

32. IRAC (2011) Prevention and Management of Insecticide Resistance in Vectors of Public Health Importance. Insecticide Resistance Action Committee, $2^{\text {nd }}$ (Edn.), Bill \& Melinda Gates Foundation, Seattle, USA, pp: 1-50. 